\title{
An Empirical Study on the Consumer Perceived Value of Online Financial Products Based on Grounded Theory
}

\author{
Qiongwei $\mathrm{Ye}^{1}$, Weiyao Kang ${ }^{1}$, Yumei $\mathrm{Luo}^{2, *}$ and Xiaoyu $\mathrm{Ma}^{3}$ \\ ${ }^{1}$ Business School Yunnan University of Finance and Economics, China \\ ${ }^{2}$ College of Business and Tourism Management, Yunnan University, China \\ ${ }^{3}$ International Business School, Beijing Foreign Studies University, Beijing, China \\ *Corresponding author
}

\begin{abstract}
The deep integration of information technology and financial market has boosted the rapid development of Internet-based financial services in recent years. Consumer perceived value of online financial product and its formation mechanism is of vital importance to the online financial enterprises of gaining its sustainable competitive advantage. To study consumer perceived value of online financial products, the study selected 32 target consumers to interview and study the objects based on grounded theory. Through open coding, relational coding, and selective coding process and on the basis of literature research, the consumer perceived value of online financial products is divided into five dimensions: economic value, attribute value, social value, experiential value and platform function value, constructing the conceptual model of consumer perceived value of online financial product. Through the empirical analysis of the 306 samples, the research results were confirmed through qualitative research based on grounded theory. The study shows that economic value, attribute value and functional value of financial products are the concerned most by consumers. Finally, some useful countermeasures and suggestions of conducting accurate and effective marketing and channel expansion oriented by consumers for financial management platform and online financial enterprises are put forward.
\end{abstract}

Keywords-online financial products; grounded theory; perceived value; empirical study

\section{INTRODUCTION}

With the increasing number of China's Internet users, the Internet technology' promotion and the depth of inclusive financial concept to the public finance, both contribute to the online financial services presenting the trend of intellectualization, scene, mobile, platform, etc. Localized products at the same time, such as Yuebao, Baidubao makes network products have higher profit, low purchase starting point, efficiency, transparence and redemption, which is suitable for consumers' scattered money management, stimulating the enthusiasm of the netizens' small-scale financial investment. By December 2017, the number of users purchasing online financial products in China had reached 129 million, increase 30.2 percent year on year, and 3.2 percentage points higher than the same period last year ${ }^{[1]}$. At the same time, the study of online finance and other problems is becoming a hot topic.
At present, researches on Internet finance at home and abroad mainly focus on characteristics analysis of online financial products, risk control and supervision, etc., while researches from the perspective of individual consumers are relatively scarce. In China, online finance is still at the initial stage of development. Compared with the maturity of traditional financial products, online financial products are still being studied in its design and marketing. So it is necessary to study users from consumer perspective and analyze consumer perceived value on online financial products, helping enterprises to design products that meet the market demand, promoting Internet financial enterprises to improve their competitive advantage and its comprehensive competitive ability. Studies of the connotation and denotation of the perceived value on online financial products is still not clear, therefore, it is necessary to adopt qualitative research based on grounded theory, particularly with specific products and scene to deeply explore the consumers perceived value based on financial product factors and its influence mechanism, in order to enrich the application of perceived value to online finance. It is hoped that it can provide references for product strategic planning and operation decision-making of financial management platforms and online financial enterprises, and provide decision-making suggestions for the Internet financial supervision department to prevent and control financial risks.

\section{THEORETICAL BASIS}

\section{A. Research on Internet Financial Products}

With the rapid development of cloud computing, big data, and emerging network technologies such as artificial intelligence, integration of Internet and traditional financial form are constantly innovate public financial theory and consumption patterns. The Internet financial management as an important part of the Internet finance is combination of advanced Internet technology such as cloud computing, big data, search engines, which is combined with the traditional financial management in order to provide customers with diversified financial services ${ }^{[2]}$. At present, domestic and foreign scholars mainly focus on the legal supervision, risk prevention and the willingness of consumers purchase online financial services. Allameh ${ }^{[3]}$ found that there was a significant positive correlation between the security of online information 
system and investors' online financial management behavior. When Qiongwei $\mathrm{Ye}^{[4]}$ studied the consumers purchase intention of perceived value on online finance, the relationship between social capital and consumer online financial decisions were analyzed, Zhang Ping ${ }^{[5]}$ pointed out that with the spread of the online financial innovation, perfecting the supervision system of heavy penalties was the vital guarantee to realize the compliance innovation path. Xie Zhichun ${ }^{[6]}$ analyzed the impact of Internet financial innovation on product brand building and proposed specific models for commercial banks. Based on the literature review, consumer perspective and grounded theory, the influence factors of perceived value dimension and intrinsic value according to the specific online consumption of consumer were analyzed.

\section{B. Research on Perceived Value}

The theory of customer perceived value originated from the theory of competitive advantage. Michael Porter ${ }^{[7]}$ believed that the competitive advantage of enterprises should be dominated by the customer-oriented value chain, and customers were the judges of the core value of enterprise products. Since then, perceived value has been endowed by scholars with special meanings and specific dimensions from different perspectives of sensibility and rationality. Zeitham ${ }^{[8]}$ pointed out that from the perspective of consumer rationality perceived value was a comprehensive assessment of perceived benefits and sacrifices of products. Day ${ }^{[9]}$ analyzed perceived value from a rational perspective and considered it as the difference between perceived benefits and perceived costs of customers. Woodruff ${ }^{[10]}$ pointed out that from the perspective of consumers' perception, perceived value was the consumers' cognition of the expected results of products or services and satisfaction of their desire by purchasing products or services. Chandon $^{[11]}$ pointed out that perceived value included utilitarian value and hedonistic value after combining the rational perspective and perceptual perspective of consumers. When thinking about customers' inherent emotional needs, scholars decomposed their perceived value into multiple dimensions. Sheth ${ }^{[12]}$ thought that consumers perceived value to cigarettes including functional value, emotional value, cognitive value, social value and restrained value. Sweeney ${ }^{[13]}$ studied durable goods and found that their perceived values were price value, quality value, emotional value and social value. Based on the comprehensive study on the meaning and dimensions of perceived value, it can be found that perceived value is a complex concept containing subjective concept. Based on the analysis of the perceived value of overall context, the thesis puts forward that consumers perceived value in the process of investment network products including not only the value of the product itself, but also the value of the consumers provided in the process of the cognition and experience from the investment. Therefore, the study adopts grounded theory as a method to explore consumer perceived value which is based on the specific dimensions of network financial product, in order to further clarify the logical relationship between various variables, studying the key factors of network consumer perceived value in the process of wealth management products.

\section{Grounded Theory}

Grounded Theory was founded in 1967 by the American sociologist Barney Glaser and Ms. Anselm Strauss. This is for the first time grounded theory has been put forward. They argued that grounded theory was on the basis of the data collection and developed from the inductive conclusion rather than on the basis of hypothesis deductive in the existing theory ${ }^{[15]}$. From the perspective of historical development, the emergence of grounded theory has established a bridge between theoretical research and empirical research in social science. Strauss ${ }^{[16]}$ believed that grounded theory should adopt open-ended interviews, literature analysis, participatory observation and other methods under natural environment. The research of social phenomenon should be in details, long-term and on the basis of systematically collecting and experience three hierarchical coding for the core concepts which reflect the social phenomenon in order to summarize the theory of the proposition. It is a qualitative research method in which the research results should be inspected with the data and similar situations. After continuous development of grounded theory, its basic ideas include five points: 1) collecting data from practice and establishing theories from data; 2) research process from concrete to abstract; 3) constantly comparing methods and applying them to theoretical sampling; 4) researchers having theoretical sensitivity; 5) taking everything as data. That is, in the field of substantive research anything about the researchers involved can be constantly compared as data to form concepts and eventually explore the involving patterns $^{[17]}$. As a unique research method, Gibson emphasized the five core principles of grounded theory: openness, explanatory power, generation and justification, theoretical structure and research process ${ }^{[18]}$. Therefore, the thesis follows the basic ideas and principles of grounded theory, studying the specific dimensions of consumer perceived value of the online financial product and the key factors of consumer perception in the process of network wealth management products.

\section{RESEARCH DESIGN}

\section{A. Research Method}

The thesis applied grounded theory to analyzing the factors influencing the perceived value of online financial products. Grounded theory as a widely used qualitative method refers to the method which uses the raw data collected by "bottom-up" way to systematically analyze, code data and extract core category in order to get the new theory. The core of the theory is derived from the analysis and research of original data and observation data, rather than deducing and form theoretical hypotheses from existing studies. The present online financial product research is at its the primary exploration stage, previous related research of online financial product perceived value is less, lacking of systematically and scientifically analysis of consumer perceived value on online financial product. As a result, the thesis applied the method of grounded theory research to exploring the connotation and framework of consumer perceived value on online financial products, seeking out the related deep influence mechanism and to do the empirical study on the basis of building consumer perceived value construction model on online financial products.

\section{B. Data Collection and Collation}

For social science research, compared with other investigation methods, interview is easier to get real 
information directly. It is more flexible in the process of research, which is helpful to deeply analyze the research question. For the purpose of the study, the unstructured and semi-structured interviews were applied. The interview can promote the conversation atmosphere, improving the initiative, adaptability of both sides. The information got from interviews is considerable flexibility and openness. The interviewer can deeply understand the specific situation in a certain moment of the record during the interview including the interviewee's external expression changes and psychological reaction. According to the survey baseline, focus group interview lead the respondents to inspire each other, have a comprehensive discussion and under the mode of divergent thinking to profoundly reveal the inner mechanism of the consumers perceived value for network products. In order to understand the consumer's feeling in the process of purchase decisions making for network financial product, we conducted unstructured and semi-structured one-on-one interviews with 32 interviewees, including focus group interviews with 5 people. The time of individual interview is 30-50 minutes, and the time of focus interview time is 100 minutes. The main content of the interview is concerning how consumers choose the financial management platform, what kind of Internet financial products they like and the overall feeling in the investment process. Interviews topics selected are about what respondents is interested in and familiar with. Therefore, the interview processes run smoothly. Respondents answered the questions according to their own understanding as much as possible. They cut into the topic quickly and the goal of gathering data was achieved. The interview data was classified, selecting 25 products users' data to do modeling analysis, 7 products users' data were used to do saturation test based on the modeling analysis, which made the overall design scientific and comprehensive.

TABLE I. BASIC INFORMATION OF RESPONDENTS

\begin{tabular}{|c|c|c|c|}
\hline & & Number of people & Percentage \\
\hline \multirow{2}{*}{ Gender } & Male & 18 & $56 \%$ \\
\hline & Female & 14 & $44 \%$ \\
\hline \multirow{4}{*}{ Age } & $20-25$ & 11 & $34 \%$ \\
\hline & $26-30$ & 9 & $28 \%$ \\
\hline & $31-40$ & 8 & $25 \%$ \\
\hline & Above 40 & 4 & $13 \%$ \\
\hline \multirow{3}{*}{ Education background } & Bachelor degree & 16 & $50 \%$ \\
\hline & Master degree & 11 & $34 \%$ \\
\hline & Doctor degree & 5 & $16 \%$ \\
\hline \multirow{3}{*}{ Profession } & Student & 19 & $59 \%$ \\
\hline & Teacher & 3 & $10 \%$ \\
\hline & Company white-collar & 10 & $31 \%$ \\
\hline
\end{tabular}

\section{Research Process}

The research based on grounded theory is divided into three stages: data collection, coding and theory establishment. The coding stage includes open coding, associative coding and selective coding. The thesis did analysis strictly according to the standard steps.

(1) Open coding. As the first step in the coding stage, open coding involves decomposing, comparing and coding the original interview data, abstracting and categorizing the concepts. The purpose is to create a self-coding table, define relevant concepts and mining areas. After obtaining the original data of in-depth interview, qsr-nvivo11.0 was used in the coding stage. The software is mainly based on qualitative analysis and relevant coding work. A total of 3 coders participated in the coding process, after discussing and reaching a consensus on the basic concepts and coding forms of perceived value. Three phase including open coding, relational coding and selective coding were carried by the first author of the thesis; other two coders inspected the coding. The purpose is to guarantee the reliability of the coding. At first, we obtained 366 free nodes. As a result of the existence of some identical aspects of interviewees' psychological feelings and contents unrelated to the research topic, finally 310 nodes were retained after selection. After classifying, combining and abstracting these nodes, 11 categories and 38 concepts were obtained and were shown in Table 2.

TABLE II. RESULTS OF OPEN CODING

\begin{tabular}{|c|c|c|c|}
\hline Number & Category & $\begin{array}{l}\text { Number of } \\
\text { reference } \\
\text { node }\end{array}$ & Concept \\
\hline 1 & $\begin{array}{l}\text { platform service } \\
\text { quality }\end{array}$ & 32 & $\begin{array}{l}\text { platform intelligent recommendation products to meet the self-need; customer } \\
\text { service timely and considerate; highly transparent and clearly described } \\
\text { financial products on the platform.; details of product details are humanized }\end{array}$ \\
\hline 2 & $\begin{array}{l}\text { platform service } \\
\text { convenience }\end{array}$ & 30 & $\begin{array}{l}\text { financial products clear classification; payment transaction process smoothly; } \\
\text { payment methods diversity; }\end{array}$ \\
\hline 3 & $\begin{array}{l}\text { platform trade } \\
\text { reliability }\end{array}$ & 25 & $\begin{array}{l}\text { more users of financial management platform; rich types of financial } \\
\text { products; normal payment redemption period; good reputation platform }\end{array}$ \\
\hline 4 & $\begin{array}{l}\text { sense of economic } \\
\text { return }\end{array}$ & 31 & $\begin{array}{l}\text { short redemption time; capital preservation and appreciation; improving the } \\
\text { utilization rate of scattered funds; reasonable price }\end{array}$ \\
\hline 5 & $\begin{array}{l}\text { investment pleasure } \\
\text { experience }\end{array}$ & 21 & investment process pleasant; product design interesting \\
\hline 6 & $\begin{array}{l}\text { interactive sharing } \\
\text { perception }\end{array}$ & 22 & $\begin{array}{l}\text { sharing investment experience; reliable financial products recommendation; } \\
\text { answer questions; high quality interaction }\end{array}$ \\
\hline
\end{tabular}




\begin{tabular}{llll}
7 & 29 & $\begin{array}{l}\text { sharing investment experience; } \\
\text { disclosure of personal identity information; earnings fluctuate greatly and } \\
\text { unstable; lacking legal protection } \\
\text { corporate reputation well; financially sound; scale large; no negative news; } \\
\text { stable structure } \\
\text { financial products profit high; strong liquidity; regular dividends }\end{array}$ \\
9 & $\begin{array}{l}\text { product reputation } \\
\text { perception } \\
\text { product revenue } \\
\text { perception }\end{array}$ & 36 & $\begin{array}{l}\text { accord with personal preference; getting recommendations from others; } \\
\text { recognition; large number of buyers }\end{array}$ \\
10 & $\begin{array}{l}\text { investment identity } \\
\text { sense of cognitive } \\
\text { innovation }\end{array}$ & 25 & personalized products; personal knowledge enrichment; innovation \\
\hline
\end{tabular}

(2) Relational coding. Relational coding is axial coding. Its purpose is to analyze the formation of the relevant concepts and categories types from the open coding, finding and establishing various relationships between concepts and category. When establishing a relationship, it is necessary to analyze and compare the conceptual level of each category according to the certain logical relationship, and combine them under the condition of no repetition and no omission. Summarizing the concept connotation around the center of the main category, and deeply abstracting related concepts of open coding formation from Table 2, finally network products consumers perceived value reduced to five dimensions (see Table 3)

TABLE III. RESULTS OF RELATIONAL CODING

\begin{tabular}{lll}
\hline Number & Axial coding & Influence category \\
\hline 1 & Economic value & sense of economic return \\
2 & Attribute value & risk perception; product reputation perception; product revenue perception \\
3 & Social value & investment identity; interactive sharing perception \\
4 & Experiential value & investment pleasure experience; innovation cognition sense \\
5 & Platform functional value & platform service quality; platform service convenience; platform trading reliability \\
\hline
\end{tabular}

(3) Selective coding and test of theoretical saturation. Selective coding is to summarize the core category in the form of "story line" to be in connection with the other categories, test and analyze the relationship among them, providing full specification for some incomplete category. Based on the diversified theory of consumer perceived value and the analysis of the above research, the central category of the influence dimension of consumer perceived value on online financial products was determined. Theoretical framework for the consumer perceived value dimension on online financial products was constructed, as shown in Figure 1.

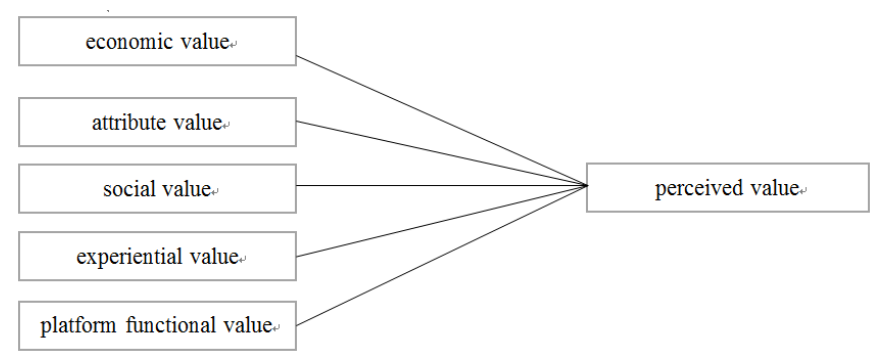

\section{FIGURE I. CONSUMER PERCEIVED VALUE DIMENSIONS ON} ONLINE FINANCIAL PRODUCTS

The coding results of the coding analysis concerning the selected seven respondents information is still in modeling framework, and there is no new category, concept appear, which can be concluded that the theory of consumer perceived value dimension model about online financial product is saturated.

\section{Results Analysis}

Based on grounded theory, qualitative analysis of the respondents' data includes analyzing, coding and theoretical saturation test etc. The thesis identified consumer perceived value on online financial products including five dimensions: economic value, attribute value, social value, experiential value and platform function value.

(1) Economic value refers to consumers' perception about economic return on investment in financial products, which originated from the sense of economic return. Consumers would like to purchase the online financial products whose purpose is to improve the utilization rate of scattered capital, capital can be maintained and added, low price with high quality. (2) Attribute value is consumers' perception of the utility value of the online financial product itself. The value reflects the financial product its own characteristics, including product profitability, risk, brand assets and dividends on a regular basis. The attribute value of financial products is the basis of financial products and the most direct judgment from consumers on the products themselves. (3) Social value means that when investing in online financial products, consumers can be evaluated by others and recognized by the society, and at the same time can get certain utility through communication and interaction in the process of investment, such as gaining high evaluation from friends; getting recommendation from others; exchanging investment experience, etc. Sweeney ${ }^{[13]}$ believed that customers gain social recognition and praise from others in the process of purchasing products, which improved their self-concept ability. The scholar Lages ${ }^{[19]}$ also pointed out that consumer perceived value included the value of comfortable life, social relationship value and social recognition value. (4) Experiential value is interactive and relative, which is related to consumers' own preferences. Tynanc $^{[20]}$ believed that consumer experience value can be created through interaction with others, which should not belong to oneself. Through analysis the consumer experience 
value on online financial products including pleasant investment experience and sense of innovation cognition, both describe psychological experience of the consumer perception on financial product investment. (5) Platform functional value. Foreign scholar Sheth ${ }^{[12]}$ believed that functional value was the utility, function and performance provided for consumers' decision. Platform functional value proposed in the thesis including the service quality of online financial products, platform service convenience and platform the trading reliability. Consumers' perception to online financial products reflects the hardware attributes that user need. When investing in online financial products, the platform should be safe enough for consumers to invest.

\section{EMPIRICAL ANALYSIS}

\section{A. Research Hypothesis and Variable Measurement}

The research based on grounded theory on has some limitations, such as the number of the sample is not enough and representative etc. Therefore, the theoretical model of the quantitative validation put forward above should be based on a large number of samples in order to achieve our research objectives. Based on the model in figure 3.1, the following hypotheses were proposed:

H1: Economic value has a significant positive impact on perceived value;

$\mathrm{H} 2$ : Attribute value has a significant positive influence on perceived value.

H3: Social value has a significant positive influence on perceived value.

H4: Experiential value has a significant positive influence on perceived value.

H5: Platform functional value has a significant positive impact on perceived value.

Variables measured include: economic value, attribute value, social value, experiential value, platform function value and perceived value, and measuring scale of item mainly comes from: (1) mature measurement terms form literature at home and abroad; (2) terms obtained through the analysis of relevant literature on online financial products and perceived value; (3) measurement terms according to the modification of the results of in-depth interviews of consumers on online financial products conducted by the author. Based on the reference from Sheth, Sweeney, and other scholars' scales and in combination with the specific situation of the study, appropriate modifications were made and 23 measurement terms were formed. Among them, economic value, attribute value, social value, experiential value and platform functional value each contains three, four, four, five and four measurement terms, and perceived value contains 3 measurement terms.

Research questions of the questionnaire designed in the study adopted 5 scale measurement of the Likert scale, from 1 to 5 scores respectively represent strongly disagree, agree, uncertain, agree and strong agree ${ }^{[21]}$. The survey subjects were rated according to the difference in the degree of agreement between specific questions in the questionnaire and their investment experience concerning online financial management.

\section{B. Data Collection}

Questionnaire was adoptd to obtain data in the study. The survey was conducted among consumers who had purchased online wealth management products such as online banking, ant wealth and Jingdong finance. Online questionnaires and paper questionnaires were formed through Questionnaire Star online platform. Electronic questionnaires were distributed to various financial communities from Internet financial enterprises, the paper questionnaires were distributed to bank offices and schools. Respondents who actually filled out the questionnaire would be given small gifts or red envelopes. A total of 378 questionnaires were collected in this survey. After removing the invalid questionnaires, 306 valid questionnaires were obtained. Participants were aged between 18 and 50 years old: $45.63 \%$ males and $54.37 \%$ females.

\section{Data Analysis}

Reliability Test. Reliability as credible degree of the measurement is used to measure consistency, stability and reproducibility of the test results. After repeated measurements on the same thing, the credible result should always remain stable. Based on internal consistency coefficient (Cronbach' $\alpha$ ) to check the consistency of the questionnaire and according to advice from scholars Nunaally and Bemstein, when coefficient alpha $>0.700$, it represents well internal matching of the measurement, the measurement reaches an acceptable level. The results of the reliability test were all greater than 0.700 , indicating that the scale proposed in the paper has a high reliability (see Table 4). However, after deleting the indicator EXV4, the reliability of the variable EXV is 0.882 , which is greater than the factor reliability which is 0.877 before EXV4 is deleted. Therefore, EXV4 is deleted.

TABLE IV. CRONBACH VALUE OF FACTORS

\begin{tabular}{lccc}
\hline Factor & $\alpha$ value & Measure term & $\begin{array}{l}\text { Measure term (after deleting the } \\
\boldsymbol{\alpha} \text { value of the factor) }\end{array}$ \\
\hline Perceived value & & PEV1 & 0.908 \\
(PEV) & 0.913 & PEV2 & 0.886 \\
& & PEV3 & 0.892 \\
Economic value & & ECV1 & 0.756 \\
(ECV) & 0.846 & ECV2 & 0.735 \\
Attribute value & & ECV3 & 0.832 \\
(ATV) & 0.902 & ATV1 & 0.893 \\
& & ATV2 & 0.877
\end{tabular}




\begin{tabular}{|c|c|c|c|}
\hline & & ATV3 & 0.880 \\
\hline & & ATV4 & 0.869 \\
\hline \multirow{5}{*}{$\begin{array}{l}\text { Social value } \\
\text { (SOV) }\end{array}$} & \multirow{5}{*}{0.862} & SOV1 & 0.819 \\
\hline & & SOV2 & 0.847 \\
\hline & & SOV3 & 0.826 \\
\hline & & SOV4 & 0.844 \\
\hline & & EXV1 & 0.844 \\
\hline \multirow{4}{*}{$\begin{array}{l}\text { Experiential value } \\
\text { (EXV) }\end{array}$} & \multirow{4}{*}{0.877} & EXV2 & 0.861 \\
\hline & & EXV3 & 0.835 \\
\hline & & EXV4 & 0.882 \\
\hline & & EXV5 & 0.831 \\
\hline \multirow{4}{*}{$\begin{array}{l}\text { Platform } \\
\text { value } \\
\text { (PFV) }\end{array}$} & \multirow{4}{*}{0.898} & PFV1 & 0.843 \\
\hline & & PFV2 & 0.851 \\
\hline & & PFV3 & 0.865 \\
\hline & & PFV4 & 0.828 \\
\hline
\end{tabular}

Validity test. Validity includes convergent validity and discriminant validity to reflect the accuracy of the questionnaire. PLS-Graph3.0 software is used to test the reliability and validity of the scale and conduct confirmatory factor analysis (CFA) of measurement model. The results can be seen in Table 5, standard load values of all factors are higher than 0.70 , and significant at 0.001 level, the average extraction variance of each factor (average variance extracted, AVE) are higher than 0.50 , all other factors of composite reliability (composite reliability, CR) are greater than 0.70 , which indicate that the measure term has good convergent validity.

TABLE V. ANALYSIS OF CONVERGENCE VALIDITY

\begin{tabular}{|c|c|c|c|c|}
\hline Factor & Measure term & Factor load & Average extraction variance & Composite reliability \\
\hline \multirow{3}{*}{$\begin{array}{l}\text { Perceived value } \\
\text { (PEV) }\end{array}$} & PEV1 & 0.853 & \multirow{3}{*}{0.803} & \multirow{3}{*}{0.920} \\
\hline & PEV2 & 0.908 & & \\
\hline & PEV3 & 0.898 & & \\
\hline \multirow{3}{*}{$\begin{array}{l}\text { Economic value } \\
\text { (ECV) }\end{array}$} & ECV1 & 0.886 & \multirow{3}{*}{0.764} & \multirow{3}{*}{0.904} \\
\hline & ECV2 & 0.892 & & \\
\hline & ECV3 & 0.844 & & \\
\hline \multirow{4}{*}{$\begin{array}{l}\text { Attribute value } \\
\text { (ATV) }\end{array}$} & ATV1 & 0.817 & \multirow{4}{*}{0.720} & \multirow{4}{*}{0.928} \\
\hline & ATV2 & 0.854 & & \\
\hline & ATV3 & 0.845 & & \\
\hline & ATV4 & 0.882 & & \\
\hline \multirow{4}{*}{$\begin{array}{l}\text { Social value } \\
\text { (SOV) }\end{array}$} & SOV1 & 0.830 & \multirow{4}{*}{0.646} & \multirow{4}{*}{0.902} \\
\hline & SOV2 & 0.769 & & \\
\hline & SOV3 & 0.808 & & \\
\hline & SOV4 & 0.763 & & \\
\hline \multirow{4}{*}{$\begin{array}{l}\text { Experiential value } \\
\text { (EXV) }\end{array}$} & EXV1 & 0.871 & \multirow{4}{*}{0.741} & \multirow{4}{*}{0.925} \\
\hline & EXV2 & 0.852 & & \\
\hline & EXV3 & 0.861 & & \\
\hline & EXV5 & 0.845 & & \\
\hline \multirow{4}{*}{$\begin{array}{l}\text { Platform functional } \\
\text { value } \\
\text { (PFV) }\end{array}$} & PFV1 & 0.913 & \multirow{4}{*}{0.872} & \multirow{4}{*}{0.929} \\
\hline & PFV2 & 0.905 & & \\
\hline & PFV3 & 0.901 & & \\
\hline & PFV4 & 0.922 & & \\
\hline
\end{tabular}

The test of discriminant validity is shown in Table 6. It can be seen that the square root of the variance of the average extraction of each factor (boldface number on the diagonal line in the table) are greater than the correlation coefficient with other factors, indicating factor measurement models has good validity.

TABLE VI. ANALYSIS OF DISCRIMINANT VALIDITY

\begin{tabular}{ccccccc}
\hline & $\begin{array}{c}\text { Perceived } \\
\text { value } \\
(\mathbf{P E V})\end{array}$ & $\begin{array}{c}\text { Economic } \\
\text { value } \\
(\mathbf{E C V})\end{array}$ & $\begin{array}{c}\text { Attribute value } \\
(\text { ATV })\end{array}$ & $\begin{array}{c}\text { Social value } \\
(\text { SOV })\end{array}$ & $\begin{array}{c}\text { Experiential } \\
\text { value } \\
(\mathbf{E X V})\end{array}$ & $\begin{array}{c}\text { Platform functional } \\
\text { value } \\
(\mathbf{P F V})\end{array}$ \\
\hline PEV & $\mathbf{0 . 9 5 8}$ & & & & & \\
ECV & 0.756 & $\mathbf{0 . 8 7 5}$ & & & & \\
ATV & 0.762 & 0.677 & $\mathbf{0 . 8 4 9}$ & & & \\
SOV & 0.624 & 0.454 & 0.580 & $\mathbf{0 . 8 0 6}$ & & \\
EXV & 0.823 & 0.735 & 0.681 & 0.716 & $\mathbf{0 . 9 0 2}$ & $\mathbf{0 . 9 0 9}$ \\
PFV & 0.722 & 0.607 & 0.610 & 0.558 & 0.681 & \\
\hline
\end{tabular}




\section{Hypothesis Testing}

Pls-graph3.0 software is used to test the structural model in the study. The specific path coefficient and significance are shown in Table 7. The standard path coefficient between economic value and perceived value is 0.433 , which is significant at the probability level of 0.001 . Therefore, hypothesis $\mathrm{H} 1$ is verified. The standard path coefficient of attribute value to perceived value is 0.421 , which is significant at the probability level of 0.001 . Thus, hypothesis $\mathrm{H} 2$ is verified. The standard path coefficient from social value to perceived value is 0.202 , which is significant at the probability level of 0.01 . Therefore, hypothesis H3 is verified. The standard path coefficient between experiential value and perceived value is 0.315 , and is significant at the probability level of 0.01 . Therefore, hypothesis $\mathrm{H} 4$ is verified. The standard path coefficient from platform functional value to perceived value is 0.497 , which is significant at the probability level of 0.001 . Thus, hypothesis H5 is verified.

TABLE VII. HYPOTHESIS TESTING OF PERCEIVED VALUE

\begin{tabular}{|c|c|c|c|c|c|}
\hline Path & $\begin{array}{l}\text { Economic } \\
\text { value } \\
\text { Perceived } \\
\text { value }\end{array}$ & $\begin{array}{l}\text { Attribute } \\
\text { value } \\
\text { Perceived } \\
\text { value }\end{array} \rightarrow$ & $\begin{array}{l}\text { Social } \\
\text { value } \\
\text { Perceived } \\
\text { value }\end{array} \rightarrow$ & $\begin{array}{l}\text { Experiential } \\
\text { value } \\
\text { Perceived } \\
\text { value }\end{array} \rightarrow$ & $\begin{array}{c}\text { Platform } \\
\text { functional value } \\
\text { Perceived } \\
\text { value }\end{array}$ \\
\hline $\begin{array}{c}\text { Path } \\
\text { coefficient }\end{array}$ & $0.433^{* * *}$ & $0.421^{* * *}$ & $0.202^{* *}$ & $0.315^{* *}$ & $0.497^{* * *}$ \\
\hline
\end{tabular}

\section{RESEARCH CONCLUSIONS AND PROSPECTS}

\section{A. Conclusions}

Based on grounded theory, the online financial product investors were firstly selected as the research objects to do interviews. Through the analysis of the interview results, specific dimensions of consumer perceived value on online financial products were constructed. Then according to the related research results, hypotheses were put forward and questionnaire was designed. Based on the questionnaire data, structural equation model and empirical test, it is concluded that the online financial product dimensions of consumer perceived value including economic value, attribute value, social value, experiential value, and platform function value, and all dimensions had significantly positive influence on consumer perceived value. Through the study of specific dimensions on consumer perceived value and analysis of the way of improving the consumer perceived value on online finance through financing platform and related financial enterprises, some meaningful enlightenment can be obtained: (1) Guarantee platform quality, create deep communication. After the analysis of the influence mechanism about specific dimensions of consumer perceived value, it is known that the most important factors that affect consumer perceived value is platform function value. Consumers concerns most about safety and quality of online financial products from the platform. The security level, service quality and product layout of the platform are all key factors that influence consumer perceived value. Therefore, online finance platform should pay attention to the platform function construction, improve transaction security of the platform, improve science and service convenience of the products, satisfy consumer to the maximum degree, create a depth communication under the consumption environment. (2) Attach importance to product design, locate customer needs; the research results of this paper indicate that consumers attach importance to the profitability, risk, brand assets and other product attributes of online financial products. So for Internet financial enterprises, it is necessary to have a good command of the market and focus more on consumers' opinion after their purchase related products including information generated from sharing and comments, regularly visit in order to accurately locate the customer requirements, realize the promotion of consumer perceived value, lay a foundation for products promotion and market development. (3) Build the theme related board of financial management to create shared value. The study illustrated the social value and experience value both had positive influence on perceived value, information sharing is the main reason for the user to interact through online financing platform, platform businessmen may establish board to attract like-minded users to join according to different subjects. Accumulating the information resources of financial products to form a huge database, through the various ways to encourage members to discuss, share, and strive for common objectives, this would strengthen the members' perception of online financial products so that consumers would constantly purchase, which improves the user viscosity.

\section{B. Limitations}

Meaningful results were obtained in the study. Because of privacy protection, difficulty of data acquisition and personal effort, the study still has some limitations: (1) the number of samples and sample representation is not enough; 378 questionnaires were collected in the study, 306 questionnaires were valid. Although meeting the basic requirements of the structural equation analysis compared with entire consumers of online financial products, it is still not enough.

Convenient sampling was adopted in the study and questionnaires were published on the Questionnaire Star platform to be filled in. The samples consisted of students, staff and half sample from Guangzhou. Therefore, the sampling would not be able to fully represent the entire users. (2) Insufficiency depth of model construction; Based on grounded theory, this study established the conceptual model of consumers based on the perceived value on online financial management, the influence of various dimensions were taken into consideration, but lacked of refinement process. For 
example, each dimension is refined by means of quantitative analysis to overcome the subjectivity of survey objects to the questionnaire.

\section{Research Prospects}

Currently, among the researches related to online finance there is no specific research from the perspective of consumer perceived value. Based on grounded theory, specific dimensions of consumer perceived value on financial product were presented. Empirical test was carried out. Finally conclusions were obtained, which was the mechanism of the specific dimensions' effects on perceived value and perceived value being expanded to a certain extent to the application of online financial products. However, the mechanism of external environmental factors and perceived value on the behavior of consumers on online financial products under specific consumption scenarios were not taken into account in the study, which can be further studied in the future.

\section{ACKNOWLEDGEMENT}

This research was supported by Yunnan Province Young Academic and Technical Leader candidate Program (2018HB) ,Yunnan Science and Technology Fund (2017FA034, 2014FB116), Yunnan Provincial E-Business Entrepreneur Innovation Interactive Space (2017DS012), Kunming Key Laboratory of E-Business and Internet Finance (2017-1A14684, KGF [2018]18), Educational and Teaching Reform Fund of Yunnan University(2015), Yunnan Provincial EBusiness Innovation and Entrepreneurship Key Laboratory of colleges and universities (YES 2014 [16]), the National Natural Science Foundation of China under Grant (71602011, 71402159, 71162005, 71362016), the Fundamental Research Funds for the Central Universities (Grant No. 2015QD009)

\section{REFERENCES}

[1] Statistical Report on Internet Development in China, 2018, http://www.cnnic.net.cn/hlwfzyj/hlwxzbg/hlwtjbg/201803/t20180305_7 $\underline{0249 . \mathrm{htm}}$

[2] Taozhen. An Empirical Study of Influencing Factors on Internet Financial Products Purchase Intention. Anhui University 2016, 10:1-55.

[3] Allameh S M, Jafri N, Esfahani S S. The Essential Infrastructure preparation Assessment For Establishing An Electronic Stock Exchange In Iran. International Journal of Management \& Information System, 2010 (14): 5-15.

[4] Qiong-wei YE, Wei-yao KANG and Yun-mei LUO, The Influential Factor of Financial Products in Social Network Environment. Academic Journal of Computer Science and Engineering, 2017(CIMNS).

[5] Zhang Ping, Dang Huaiqing. Strategic Mismatch and Regulatory Mechanism in Internet Financial Innovation Diffusion [J].Management World, 2015(09):170-171.

[6] Xie Zhichun. Internet Financial Innovation and Brand Building Model of Commercial Banks [J]. China Soft Science, 2016(06):159-170.

[7] PORTER M. Competitive advantage: creating and sustaining superior performance. Free Press, 1985.

[8] ZEITHAML V A. Consumer perceptions of price, Quality and Value: A Means 2EndModel and Synthesis of Evidence. Journal of Marketing, 1988, 52(3):2-22.

[9] DAYG S. The Capability of Marketing-Driven Organizations. Journal of Marketing, 1994, 58(10):37-52.

[10] Flint D J, Woodruff R B, and GARDLAL S F. Customer value change in industrial marketing relationships: a call for new strategies and research. Journal of Industrial Marketing Management, 1997, 26(2): 163-175.

[11] Chandon, Pierre, B. Wansink, and G. Laurent. A Benefit Congruency
Framework of Sales Promotion Effectiveness. Journal of Marketing, 2000, 64(4):65-81.

[12] ShethJN, BruceI, NewmanB, GrossL. Why We Buy What We Buy: A Theory of Consumption Values. Journal of Business Research, 1991, 22(4):159-170.

[13] Sweeney J C, Soutar N, Geoffrey. Consumer Perceived Value: The Development of a Multiple Item Scale. Journal of Consumer Research, 2001, 77(2): 203-220.

[14] Glaser B G, Strauss A L. The discovery of grounded theory: strategies for qualitative research .Chicago: Aldine, 1967: 56-70.

[15] Strauss, A, J. Corbin. Grounded theory methodology - an overview, Handbook of Qualitative Research, Sage Publications, 1994.

[16] Goulding C. Grounded theory: the missing methodology on the interpretivist agenda. Qualitative Market Research, 1998, 1(1):50-57(8).

[17] Gibson,B.\& Hartman, J.(2014).Rediscovering grounded theory. London: Sage.

[18] Lages, L. F.; Fernandes, J. C. The SERPVAL scale: a multi-item instrument for measuring service personal values. Journal of Business Research, 2005, 58(11): 1562-1572.

[19] TYNAN C, MCKECHNIE S. Hedonic Meaning Creation Though Christmas Consumption: A Review and Model. Journal of Customer Behavior, 2009, 8(3): 237-255.

[20] SHEN L Y, BAO H J, WU Y Z. Using bargaining-game theory for negotiating concession period for BOT-type contract. Journal of Construction Engineering and Management 2007, 133(5):385-392. 